\title{
Deprivation and the See-saw of Death
}

\author{
Christopher Wareham
}

\author{
School of Philosophy and Ethics \\ University of Kwazulu-Natal \\ chris.wareham@gmail.com
}

\begin{abstract}
Epicurus argued that death can be neither good nor bad because it involves neither pleasure nor pain. This paper focuses on the deprivation account as a response to this Hedonist Argument. Proponents of the deprivation account hold that Epicurus's argument fails even if death involves no painful or pleasurable experiences and even if the hedonist ethical system, which holds that pleasure and pain are all that matter ethically, is accepted. I discuss four objections that have been raised against the deprivation account and argue that this response to Epicurus's argument is successful once it has been sufficiently clarified.
\end{abstract}

\section{Introduction}

Epicureans have advanced several arguments for the claim that death is nothing to us; that is, that death can neither harm nor benefit the person who dies. ${ }^{1}$ The argument I focus on in this paper, which I call the Hedonist Argument, holds that only the experience of pleasure or pain can benefit or harm a person. Since death cannot be experienced at all, death cannot harm or benefit the person who dies. ${ }^{2}$ This argument has several counter-intuitive consequences. Amongst other things, it undermines the common view that death is one of the worst things that can happen to a person and entails that killing does no direct harm to the victim.

In response to the Hedonist Argument, Thomas Nagel, Fred Feldman, Ben Bradley and others have formulated the deprivation account. The deprivation approach to the harm of death accommodates the hedonist claim that death is not intrinsically good or bad: deprivation theorists accept that death is neither pleasurable or painful. Instead, they claim that death is often bad because of the intrinsic goods it prevents or deprives a person of. In this paper I discuss the deprivation approach and consider some of the serious difficulties it faces. I argue that with some clarifications in place the deprivation account is defensible.

1 In my terminology there is no distinction between bad and harmful, or between good and beneficial. If something is bad for a person then it harms them and vice versa, and if something is good for a person then it benefits them and vice versa.

2 The Hedonist Argument considered here should be distinguished from Epicurus's Timing Argument and Lucretius's Symmetry Argument. The Timing Argument is contained in Epicurus's claim that 'death, the most terrible of all ills, is nothing to us, since so long as we exist death is not with us, but when death comes, then we do not exist' (Oates 1940: p. 31). Lucretius explains the Symmetry Argument as follows: '[1] ook back ... at how the stretch of unending time before we are born has been nothing to us. Nature, therefore, offers this reflection to us of the time to come after our eventual death' (Warren 2004: p. 58). I am not concerned with either of these arguments here. 


\section{The Hedonist Argument}

In his Letter to Menoeceus, Epicurus wrote,

[b]ecome accustomed to the belief that death is nothing to us. For all good and evil consist in sensation and death is the deprivation of sensation. (Oates 1940: p. 30)

This argument can be formalised as follows:

1. Death involves no experiences.

2. Only the experiences of pain or pleasure can harm or benefit a person.

Therefore death can be neither harmful nor beneficial.

Deprivation theorists accept premise 1. Assuming that death marks the end of a person's existence and that there is no afterlife, death cannot be experienced. ${ }^{3}$ Deprivation accounts attempt to undermine premise 2 .

At least two sorts of response can be made to the claim that only the experience of pleasure or pain can be harmful. First, it could be argued that the hedonist system Epicurus adopts should be rejected in favour of a different ethical system. Second, it can be claimed that premise 2 is false even on hedonist ethical theories.

The first sort of response involves rejecting the hedonist claim that pleasure and pain are the only sources of intrinsic value in favour of a different theory of well-being. According to Desire-Fulfilment Theories, for instance, what matters ethically is that a person's desires are fulfilled. On this type of theory, a person can be harmed even if she does not experience pain. A person is harmed just in case her desires are thwarted or left unfulfilled, even if she does not know about it or have any negative experiences as a result. If so, then the fact that death involves no experiences is no argument against the claim that that it can be bad for one. ${ }^{4}$ So rejecting hedonism in favour of a Desire-Fulfilment Theory is one way of undermining premise 2 above.

However, I think the second type of response to Epicurus should be preferred for two reasons. The first is one of convenience. Many philosophers, including John Stuart Mill, are sympathetic to Epicurus's brand of hedonism. ${ }^{5}$ It would thus be more convenient to avoid the difficult task of undermining an influential ethical theory. The second reason for attempting to reconcile hedonism with the claim that death can harm or benefit a person is one of inclusiveness. It is desirable to show that the Hedonist Argument fails on Epicurus's own terms. In this way, the claim that death can harm a person is broadly applicable across different ethical theories. Thus, following anti-Epicureans like Bradley and Feldman, I show that the Hedonist Argument can be undermined even if we accept the hedonist idea that pleasure and pain are the only sources of intrinsic value.

3 'Death' can mean i) the process of dying, ii) the event of permanent cessation of consciousness; iii) the state of being dead, or iv) the cessation of vital functions of the living organism. Jens Johansson (2005: p. 71) argues convincingly that death should be regarded as an event. His analysis is accepted here, although later I suggest that the vagueness about what constitutes the death event can lead to confusion.

4 Parfit (1984: p. 495), for instance, claims that on desire theories, '[i]t is irrelevant to my desire whether it is fulfilled before or after I am dead.'

5 Compare Mill (1957: p. 10-11). 


\section{The deprivation account}

Deprivation theorists agree that death cannot be harmful because of its intrinsic features. Death involves neither pleasure nor pain. Instead, death can be extrinsically harmful. That is, death is harmful because of the intrinsic goods that it prevents. ${ }^{6}$ Just as a vaccination can be beneficial if it prevents painful disease, so can death be harmful because it prevents good experiences. Epicurus's mistake lies in failing to recognise that events can be extrinsically valuable because of what they cause or prevent. Since this is so, Epicurus's second premise is false. Experiences of pain are not the only things that can harm a person. The prevention of pleasurable experiences can be extrinsically harmful.

Deprivation theorists go further than this. They claim that the extent to which an event or state of affairs is extrinsically harmful for a person is determined by a counterfactual comparison. That is, in addition to explaining whether a death is bad, deprivation theorists often attempt to give an account of how bad a particular death is. In order to determine the extent to which an event is on balance harmful, what actually happens is compared to what would have happened if the event had not occurred. A vaccination is thus extrinsically beneficial to the extent that a person is intrinsically better off than she would have been if she had not had the vaccination. Similarly, a particular death is harmful to the extent that a person would have been better off had she not died that particular death.?

This account of extrinsic value accounts for some compelling intuitions about death. For instance, it explains why it is usually thought that the death of a young person is worse for them than the death of a very old person. A young person loses more when she dies because her death deprives her of more of the pleasures of life. Similarly, deprivation theory accommodates the intuition that death can be beneficial if, for instance, it prevents continued life that would be painful to the extent that it would not be worth living. ${ }^{8}$

Despite its intuitive appeal, deprivation theory has been heavily criticised by Epicureans and anti-Epicureans alike. In what follows I discuss the main criticisms that have been levelled against the deprivation account. These criticisms fall into two categories. First I discuss the claim that death cannot conform to the comparative account of extrinsic value because death is not a suitable term of comparison. Thereafter I examine problems for the account of extrinsic value itself.

6 See Bradley (1998) for an excellent discussion of extrinsic value. Bradley argues that there are at least four types of extrinsic value: instrumental, preventive, contributory and significatory. As mentioned, the type of extrinsic value concerned here is preventive.

7 There is of course usually an epistemic difficulty in determining what would have happened if a particular event had not occurred. As McMahan (2002: p. 107) suggests, in practice we are forced to evaluate death using a 'probabilistic or statistical basis. Based on our knowledge of the way in which a certain kind of life tends to go, we can hazard a reasonable conjecture... about what a given person's future life would have held if he had not died when he did.'

8 It is worth noting that even if the deprivation account is accepted, hedonism rules out posthumous harms such as being defamed after one's death. Such events do not cause or prevent any pleasure to the person concerned and thus have no intrinsic or extrinsic value for her. On the other hand posthumous events may make a difference to the value of a person's death. For instance, if a person would have suffered defamation even had she not died, her death might be less bad because it prevents the emotional pain of being talked about badly. If this seems strange, I attribute it to a shortcoming of hedonism, rather than of the deprivation account. 


\section{The see-saw of death: a problem with death as an instance of comparative harm}

Deprivation theory can be crudely compared to a see-saw. The more intrinsic goods a person's life would have contained, the worse her death is by comparison. The value of death goes up or down in proportion to the extent to which the value of continued life goes down or up, just as one side of a see-saw rises to the extent that the other side falls.

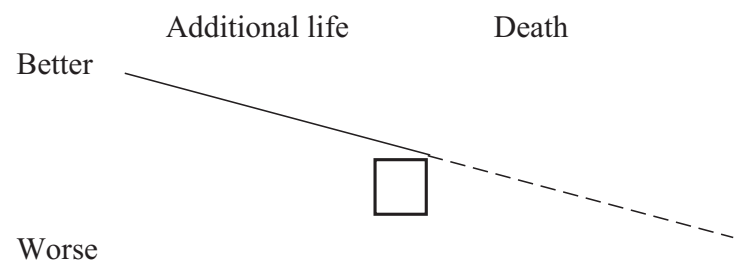

Silverstein (1980: pp. 410, 2000: pp. 119) recognises a problem with this. He argues that the claim that additional life would be good depends on the claim that additional life is better than death. If so, deprivation theorists presuppose that death can be assigned a value with which the value of continued life can be compared. This begs the question since the issue is whether death can be assigned a value at all. Thus the claim that the value of death can 'hold up' the value of continued life - to use the see-saw analogy - is cast into doubt. According to Silverstein, the claim that death is worse than continued life is unintelligible.

Another way of putting this problem is as follows. In the diagram below, line A represents a possible life in which a person, call him Hansel, does not die at $t_{1}$ and goes on to live until $t_{2}$. Line $B$ represents the actual world in which Hansel dies at $t_{1}$.

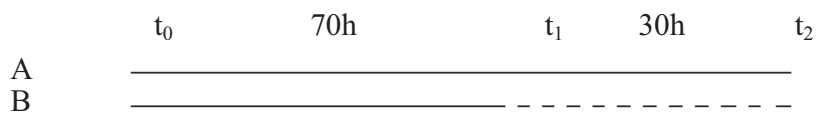

According to Silverstein, deprivation theory has us compare the value of the period $t_{1}$ to $t_{2}$ in each possible life. Suppose that if Hansel did not die at $t_{1}$ he would experience 30 additional units of hedonic good $\left(30_{\mathrm{h}}\right)$. Let's say we can assign a value of zero to the period $t_{1}$ to $t_{2}$ in which Hansel is dead in life B. In this case, Hansel's death at $t_{1}$ has an extrinsic value of -30 hedonic units $\left(-30_{\mathrm{h}}\right)$. He is made $30_{\mathrm{h}}$ worse off because of his death at $t_{1}$. Silverstein's point is that this comparison is impossible, since in life B the period $\mathrm{t}_{1}$ to $\mathrm{t}_{2}$ when Hansel is dead cannot be assigned a value - not even zero without begging the question. It is thus incoherent to say that life $\mathrm{A}$ is better from $\mathrm{t}_{1}$ to $t_{2}$ than life $B$ is. On this view, then, deprivation theory fails because it makes an illegitimate life-death comparison.

Feldman (1991) responds to Silverstein's objection by arguing that it is not necessary to compare the value of continued life to the value of death in order to determine the overall extrinsic value of a death. Rather, the extent of the harm of death is calculated by comparing the value of a whole life in which a particular death occurs to the 
value of an entire counterfactual life in which everything is the same except the death does not occur. This consideration accords with Bradley's general claim about the value of events and states:

[t]he overall value for a person $\mathrm{x}$ of an actually occurring or obtaining event or state $\mathrm{e}=$ the value of $\mathrm{x}$ 's actual life minus what the value of $\mathrm{x}$ 's life would have been had e not occurred or obtained (Bradley 2007: pp. 115).

On this account, when we calculate the value of the event of Hansel's death at $\mathrm{t} 1$, it is not necessary to make an unintelligible life-death comparison between $A, t_{1}$ to $t_{2}$ and $\mathrm{B}, \mathrm{t}_{1}$ to $\mathrm{t}_{2}$. Instead, a life-life comparison is made such that the overall value of Hansel's actual life (life B) is compared to the overall value of his life in the most similar possible world in which his death at $t_{1}$ does not occur (life A.) Suppose for example that the value of Hansel's actual life is $+70 \mathrm{~h}$. Suppose further that if Hansel had not died at $t_{1}$ his life would have had a hedonic value of $+100 \mathrm{~h}$. His death thus deprives him of 30 units of hedonic good. In this way it is possible to determine the extent to which Hansel's death is extrinsically bad for him without making a life-death comparison.

Thus far I have shown that death can be harmful if we accept that there are extrinsic harms. I have also argued that determining the extrinsic value of an event relies on making a counterfactual comparison between the value for a person of her actual life and the value her life would have had if the event had not occurred. In what follows I discuss some objections to this general conception of extrinsic harm. Clearly if the comparative account of extrinsic harm fails, then so does the deprivation account. I argue that the comparative account is defensible and thus that the deprivation account remains intact.

\section{Objections to the comparative account of extrinsic value}

The problem of selection

The account of extrinsic value holds that an event is harmful to the extent that it makes a life worse compared to the most similar counterfactual life in which the event did not occur. I will refer to this comparison as the most similar life comparison. The most similar life comparison is problematic because it appears that the most similar counterfactual life is likely to be too similar to the actual life to accommodate the compelling intuitions that make the deprivation account attractive.

Consider the example of a pedestrian, Gretel, who is hit by a bus and instantaneously killed at the age of twenty. The intuition is that Gretel's death is very bad for her. If she had not been killed she is likely to have lived a lot longer and enjoyed many more of the pleasures of life. However, it appears that the most similar life in which the particular death event did not occur is likely to be one in which Gretel is hit by the bus, but dies a few seconds later. By this comparison her death does not harm her because she is only deprived of a few seconds of life. Thus the most similar life comparison appears to be at odds with the intuition that Gretel's death is very bad for her.

This objection thus casts serious doubt on the idea that the most similar counterfactual life is the term of comparison that should be used when evaluating an event such as death. But if the most similar life comparison is rejected, it is unclear what comparison should take its place. Clearly, the relevant counterfactual possibility is one in which the particular death did not happen. There are, however, indefinitely many ways in which a person's death might have failed to occur. Gretel may, for instance, have been hit by the bus and received a non-fatal injury that left her in pain for the remainder of her life. Alternatively she might have stayed home that day and avoided the 
bus accident altogether. More fancifully, she may have been abducted by aliens a moment before the accident occurred. Comparison with any of these possibilities will yield different evaluations of Gretel's death. Thus, if the most similar life comparison is rejected there is a problem with finding a non-arbitrary way of selecting which of the many alternatives to death is the relevant term of comparison for the purposes of evaluating a person's death. I call this the problem of selection. ${ }^{9}$

At least two types of response can be made to this difficulty. The first is to determine non-arbitrary criteria for choosing between the alternatives to death. The second response is to argue that the most similar counterfactual life comparison does not entail that Gretel's death does not harm her.

McMahan adopts a version of the first approach. He claims we should reject the most similar life comparison and concede that there may be indefinitely many ways in which a person may not have died. All of these ways result in counterfactual lives that can justifiably be used as terms of comparison in the evaluation of a death. Nevertheless, he claims that we often narrow down these options by using several criteria.

Among the criteria that seem unconsciously to guide our selection of the relevant alternative are that, to the greatest extent possible, it should completely exclude the cause of death and its effects, it should give the person the best future that was open to him, it should preserve his earlier life as it actually was, and it should have been, in a suitably weak sense, a practical possibility (McMahan 2002: p. 116-117).

McMahan suggests that the unconscious use of these criteria is why we often arrive at an unequivocal evaluation of a particular death, despite the fact that there are many possible evaluations.

However, McMahan admits that the use of the above criteria is not rationally required. His aim is thus 'descriptive: to indicate how we in fact select the terms of comparison when evaluating a particular death' (2002: p. 112). That is, he does not attempt to justify the criteria that are used. Without such a justification, however, there is no reason to think that the criteria we use are correct, or yield accurate evaluations of a particular death. Thus McMahan's account does not provide a solution to the problem of selection.

I suggest that the way to undermine the problem is to defend the most-similar possible life comparison, since this would allow us to avoid a multiplicity of equally justified evaluations of a death.

As mentioned, though, it might seem that no deaths are particularly bad if we accept this comparison. This is because it appears that the most similar possible life in which the death event does not occur is likely to be one in which the person dies a second earlier or later, or is severely injured. However, this assumes an extremely narrow description of the death event. If the death event is described narrowly as the last physical cause of Gretel's being dead, such as a brain haemorrhage that causes the cessation of her life, then Gretel's death may indeed not be very bad. If the brain haemorrhage had not occurred when it did then it is likely to have occurred a second later. The most similar hypothetical life would not be much better than the life she actually has.

However, this narrow description of the death event is not the only one possible. An event can admit both narrow and broad descriptions. ${ }^{10}$ For instance, suppose that Vervet is injured. The injury event might be described as follows: 'Vervet's ear was

9 McMahan (2002: p. 107) refers to the problem of selection as the 'Metaphysical Problem.'

10 See Roberto Casati and Achille Varzi (2008) for an outline and discussion of the controversies surrounding the status of events. 
lacerated.' Alternatively, we may want to include the broader context in the description of the event. We may be more interested that 'Vervet's ear was lacerated when she was bitten by Rhesus.' An even broader description of the event of Vervet getting injured is also possible. For instance, 'Vervet's ear was bitten by Rhesus when Vervet attacked Rhesus with a battle axe.' So the injury event can be broadly or narrowly described.

Similarly, a death event can be broadly or narrowly described. In Gretel's case, it might be said that the event of her death was the final physical event that caused her to be dead. Alternatively, the death event might be construed more broadly as comprising some of the circumstances of her death, including Gretel's being hit by a bus. Each of these descriptions of the death event will yield a different evaluation of the death.

The solution to the problem of selection is thus to provide a clear description of the event to be evaluated. I think that in Gretel's case we include her being hit by the bus, as well as her dying as a result, in the description of the death event. Thus the death event that we are interested in is not just one of the many physical events involved in the shutdown of her body. Instead we are interested in a broader description of the death event: Gretel's being killed at the age of twenty by being hit by a bus. ${ }^{11}$ The relevant counterfactual comparison is between the actual life in which Gretel is killed by a bus and the most similar hypothetical life in which none of the circumstances of this death event is present. If so, her death is likely to have been very bad for her.

Thus the most similar possible life comparison can be used without resulting in the counter-intuitive claim that Gretel's death is not particularly bad for her. Retaining the most similar life comparison also allows us to avoid the unwelcome idea that many evaluations of a particular death event are equally justified. If the death event is adequately described, there is only one relevant term of comparison: the most similar life in which that death event did not occur. Since there is only one relevant possible life with which to compare the actual life, there is only one correct evaluation of the death event. The problem of choosing between various alternatives to death is thus avoided.

\section{The problem of overdetermination}

A further difficulty with comparative or extrinsic harms concerns instances in which death is overdetermined. In such cases, in which a person would have died soon as a result of a different event, the comparative account's evaluation of the person's death once again appears to be at variance with intuitions about the extent to which the event harms one.

For instance, suppose it is discovered in an autopsy that Gretel had an aneurysm from which she would have died in a week's time had she not been killed by the bus. On the deprivation account, her actual death would not be very bad for her. Since she would have died a week later anyway, her death does not deprive her of much good. The intuition, though, is that Gretel's actual death may be worse than the hypothetical death as a result of the aneurysm would have been. She dies even younger, and experiences even fewer goods because her death by bus collision comes earlier. Here it appears that the deprivation account gets an incorrect result with respect to the evaluation of Gretel's death. I will argue that the deprivation account gets the right result in such cases, and provide an explanation for the intuition that it does not.

When it asked whether the event of a person's death is bad for her, this question can mean several things. We might be asking whether the fact that a death event must oc-

11 Note that I am not claiming that this is the only correct description of the death event. I do, however, think that the death thus described is what we are interested in evaluating in this case. 
cur at all is bad for her. We might also be asking whether a particular type of death such as a premature death, or death in old age is bad for her. Alternatively the question might be whether a particular death event is bad for her: death at time $t$ in circumstances c. The term of comparison that should be used will vary depending on which question is asked. If we are interested in determining whether the fact that a person will die is bad for her, the relevant term of comparison might be a life in which the death event does not occur at all: an immortal life. ${ }^{12}$ If we are concerned with evaluating a type of death, the relevant comparison will be a life in which that type of death does not occur: for instance, one in which a person does not die prematurely. If we are looking to determine whether and to what extent a particular death event harms the person who dies, then the obvious term of comparison is the life a person would have had if that particular event had not occurred.

All of these questions are interesting, and in each case the account of extrinsic value gives the right answer once the question is clarified. The fact that a person must die at some time is harmful to the extent that an eternal life is better than a life in which one must die. In Gretel's case, the type of death she has, a premature death, is very bad for her. It is bad in comparison to a life in which neither of the causes of her premature death would have operated. If she had not died prematurely, it is likely that she would have gained more of the goods of life. Her death by bus collision is worse than her death by aneurysm because it is more premature. ${ }^{13}$ Thus I think that it is the 'type' question we have in mind when we think that Gretel's death is very bad for her.

The deprivation account's evaluation of the harm caused by Gretel's particular death is also correct. Gretel's particular death event - being hit by a bus at the age of twenty - does not harm her very severely because she would have died soon from an aneurysm. This question may be relevant in ethical decisions about killing and letting die. Suppose, for instance, we were deciding whether to save Gretel's life or the life of someone of a similar age, Pierre, who had also been hit by the bus, but did not have an aneurysm. We would want to know whose particular death would be worse for them. Since Pierre doesn't have an aneurism, his death is likely to be worse for him. Thus it might be better to save his life.

So the deprivation account arrives at the correct evaluation of particular deaths that are overdetermined. The intuition that it does not emerges when we answer a separate question about the type of death a person dies. Thus the problem of overdetermination can be undermined by clarifying which question we have in mind. ${ }^{14}$

\section{The problem of relevance}

The final difficulty I discuss is as follows. The fact that a person is comparatively worse off because of an event is not sufficient for gauging the extent of a harm and may not even be relevant to whether a person is harmed by that event. This is because there are some events that make us comparatively worse off, but which are not harms.

Suppose, for instance, I fail to win the lottery. If I had won, I would presumably be much better off than I am. Yet the claim that losing the lottery is seriously harmful

12 This is the question to which Bernard Williams (1978) offers an answer in his 'The Makropulos Case: Reflections on the Tedium of Immortality'.

13 McMahan (2002: p. 123-126) argues that defining a premature death is difficult. It involves determining what a non-premature or 'normal' life might be. This is obviously problematic, not least because a 'normal' life-span varies considerably from generation to generation and between societies. I will not pursue this question here as my central focus is the evaluation of particular deaths.

14 This response is similar to Feldman's (1991). McMahan (2004: p. 103-104) also suggests that there might be different questions and thus different comparisons at issue, but he does not discuss the possibility that intuitions about the overdetermined death of the young pedestrian might be a response to the ‘type' question. 
must surely be treated with scepticism. The comparative account of harm appears to be committed to this conclusion. ${ }^{15}$ Examples like this cast doubt on the claim that an event that makes a person comparatively worse off harms her. Thus the fact that death makes a person worse off than she would have been may not secure the claim that death harms her.

The idea that failing to win the lottery is a non-event, rather than event, fails to solve the problem; the example can simply be re-described such that the event of different lottery numbers coming out, or the event of my picking the wrong numbers, is comparatively bad for one. A different approach is required.

Deprivation theorists might accept that comparative disvalue is not a sufficient condition for harm, and attempt to give an idea of other necessary co-conditions. Alternatively, they might claim that losing the lottery is in fact a harm, in which case it seems necessary to explain the intuition that it is not. Finally, they can argue that the account of extrinsic value does not entail that losing the lottery is a harm.

Draper (1999) and McMahan (2002) suggest versions of the first response. Draper suggests a 'likelihood constraint,' while McMahan advocates a similar 'Realism Condition.' Both requirements entail that the comparative misfortune of not winning the lottery is not harmful because there was no realistic chance of winning. However, these co-conditions have implausible consequences. For example, they entail that if a person is extremely likely to suffer an injury or death, then injury or death cannot harm her. The fact that RAF pilots in the Battle of Britain were extremely likely to die should not, I think, undermine the claim that their deaths harmed them. Thus I think these versions of the first response are unsuccessful.

The second strategy is to argue that failing to win the lottery is in fact extrinsically harmful, and to provide an explanation for the intuition that it is not. One way of explaining this intuition is to claim that non-hedonist values enter into the assessment of losing the lottery. Thus although the lottery is extrinsically harmful in terms of hedonist values, its fulfilling other values might explain why we think it isn't harmful. In particular, the intuition that failing to win is not bad might be explained by the fact that the procedure is fair, since the comparative harm is equally shared between almost all the participants, or because none of the participants can reasonably expect to win, or because the winner is chosen at random. It may also be regarded as non-harmful because lottery entrants in some sense autonomously consent to the procedure. If there is an unconscious trade-off between these values and hedonic values, then the extrinsic harm of losing the lottery will appear to be mitigated. Depending on the weighting of these values, hedonistic comparative harm may appear to be completely negated. According to this response, then, failing to win the lottery is in fact harmful and intuitions to the contrary are the result of the pull of non-hedonic values that may be irrational.

I find this reply extremely unconvincing, since it entails that the lottery harms millions of people twice a week by not allowing everyone to win. Since the implication that the lottery harms people severely is so objectionable, I think this strategy should be rejected.

The final response I discuss is to argue that failing to win the lottery is not harmful overall. This claim uses elements of the previous strategy. Like the previous response it holds that other values like fairness or autonomy enter into the picture. However, hedonist proponents of the account of extrinsic value might argue that values like fair-

15 This problem of relevance is often only regarded as undermining the claim that comparative harms do not warrant any negative emotional response, and not the claim that death is bad or a harm (Bradley 2004; Draper 1999). I think that the objection is applicable to the latter claim as well. 
ness and autonomous consent are derived from hedonic values. For instance, they might argue that fairness is good because it brings pleasure or prevents or mitigates pain. Thus fairness itself is extrinsically good. If so, then the lottery involves a trade-off between different sources of hedonic extrinsic value. The extrinsic disvalue of not winning the lottery is cancelled out by the extrinsic good of having a fair procedure to decide where the money goes. In this way hedonists can claim that the account of extrinsic value does not entail that failing to win the lottery is harmful overall. If so, the problem of relevance is undermined.

\section{Conclusion}

I have argued that we should reject the Hedonist Argument for the claim that death can neither harm nor benefit the person who dies. This is so because the Hedonist Argument relies on the claim that only pleasurable or painful experiences can be beneficial or harmful for the person who dies. The account of extrinsic value proposed by deprivation theorists shows that an event can be harmful in virtue of the good experiences it prevents, even if the event does not give rise to negative experiences. This account also provides an explanation of the extent to which an event such as death can be harmful. Death is harmful to the extent that a person would have been better off if she had not died when she did.

Considering objections to the account of extrinsic value on which the deprivation account is based yielded several clarifications. First, the claim that a person would have been better off as a result of her death is to be understood, not as involving a comparison between continued life and death, but rather as requiring a comparison between a life in which a death occurs and a counterfactual life in which that death did not occur. Second, in evaluating death as an event, it is necessary to explain what circumstances are to be included in the description of the death event. Third, in asking whether death is harmful, it is important to specify whether one is asking for an evaluation of the fact that a person must die, the type of death event, or the particular death that the person has. Fourth, in assessing the hedonist account of the harm of death, it is necessary to determine whether, and the extent to which, values like fairness or autonomy should enter into the extrinsic value equation.

With these clarifications in place, the deprivation account justifies some important ethical claims. The fact that death can harm a person allows us to retain the idea that killing can do direct harm to the victim. Deprivation theory thus has important consequences for the ethics of killing. Amongst other things, it provides an explanation of how suicide and voluntary euthanasia can be rational. If a life in which a person dies soon is likely to be better than a life in which she dies later, then it might be rational to choose to die. The deprivation reply to Epicurus's Hedonist Argument can thus contribute significantly to discussion of ethical issues related to death and killing.

\section{References}

Bradley, B. 1998. 'Extrinsic Value,' Philosophical Studies, 91(2), pp. 109-126.

Bradley, B. 2004. 'When Is Death Bad for the One Who Dies?' Noûs, 38, pp. 1-28.

Bradley, B. 2007. 'How Bad Is Death?' Canadian Journal of Philosophy, 37(1), pp. 111-128.

Casati, R. \& Varzi, A. 2008. 'Events,' in Zalta, E. (ed.), Stanford Encyclopaedia of Philosophy. URL $=<$ http://plato.stanford.edu/archives/fall2008/entries/events/ $>$. 
Draper, K. 1999. 'Disappointment, Sadness, and Death,' The Philosophical Review, 108(3), pp. 387-414.

Feit, N. 2002. 'The Time of Death's Misfortune,' Nô̂s, 36, pp. 359-383.

Feldman, F. 1991. 'Some Puzzles About the Evil of Death,' The Philosophical Review, 100(2), pp. 205-27.

Johansson, J. 2005. Mortal Beings: On the Metaphysics and Value of Death, PhD Dissertation, Stockholm University.

McMahan, J. 2002. The Ethics of Killing: Problems at the Margins of Life, New York: Oxford University Press.

Mill, J.S. 1957. Utilitarianism, New York: MacMillan.

Nagel, T. 1979. 'Death', in Mortal Questions, Cambridge: Cambridge University Press, p. 1-11.

Oates, Whitney, J. 1940. The Stoic and Epicurean Philosophers, New York: Random House.

Parfit, D. 1984. Reasons and Persons, Oxford: Clarendon Press.

Silverstein, H. 1980. 'The Evil of Death,' Journal of Philosophy, 77(7), pp. 401-424.

Silverstein, H. 2000. 'The Evil of Death Revisited,' Midwest Studies in Philosophy, 24, pp. 116-135.

Warren, J. 2004. Facing Death. New York: Oxford University Press.

Williams, B. 1973. 'The Makropulos Case: Reflections on the Tedium of Immortality,' in Problems of the Self, Cambridge: Cambridge University Press, p. 82-100. 